\title{
Palliative Care and COVID-19 Modeling
}

\author{
A Systematic model of Entrepreneurs living in area' $\mathrm{X}$ ' in Nigeria. \\ Kolawole Peter Akeredolu, Nigeria.
}

\begin{abstract}
This work provides a simplified approach to Palliative care and disease modeling using the methods of Partial Differential Equations, Probability and Integration.
\end{abstract}

It gives us a picture of how a particular group of Entrepreneurs who are engaged in different business activities was further divided into three sub-groups.

The conclusion part of this work describes extensively the benefits of disease modeling in terms of Human's economic development and soundness of Health.

While it recommends the adoption of disease mathematical modeling as a contingency when considering Government's timely interventions to the People and Resource Management as it facilitates other disease modeling techniques such as Statistical and Economic.

\#Sub-

groups\#InitialConditions\#PalliativeCare\#COVID-19

Modeling\#Benefits\#Economy\#Testing\#Recovery rates\#R(t) $=\mathbf{R}(0) \mathbf{e}^{\wedge} \mathbf{k t}$

\section{Background of Study:}

Recently, COVID-19 has become the Spotlight of what to model among the Engineers and Scientists as regards the peculiarities of diseases ravaging the social system and it has now became imperative to in-put our concerted efforts to get over this Challenge.

\section{INTRODUCTION}

In this work, I shall describe ' in section 2.1',the solutions to COVID-19 Spread and it's impacts on people using the available mathematical tools and some verifiable assumptions.

Also in the later section,I will conclude with the importance of disease mathematical modeling.

\section{METHODS}

Sources:

Sub-grouping.

Tools.
Entrepreneurs in area'X'in Nigeria Wikipedia and Library

\section{RESULTS}

Sub-Groups

A1 $=$ Pub (beer parlor) owners.

A2 $=$ Super market owners.

A3 =Farm owners

\section{Assumptions}

1.) Each Sub-Group population $=1000$ People.

2.) Activities $=$ Spread rates.

3.a.)A1 Spread Rate at an instant time $(\mathrm{t})=500$ out of 1000 .

3.b.)A2 Spread Rate at an instant time $(t)=300$ out of 1000 .

3.c.)A3 Spread Rate at an instant time $(t)=200$ out of 1000 .

4.) $\mathrm{Z} 1, \mathrm{Z} 2, \mathrm{Z} 3$ are Spread Rates at instant time(t) for $\mathrm{A} 1$, A2, A3.

5.) $\mathrm{R}=$ Palliatives (Testing, Foods and Basic needs, Soaps, Hand sanitizers, Personal Protective Equipments, Grants and Loans,etc).

\section{Initial Conditions}

$\mathrm{A} 1(0)=\mathrm{A} 2(0)=\mathrm{A} 3(0)=1000$.

Partial Differential Equations

1.) $\partial \mathrm{A} / \partial \mathrm{t}=[\partial \mathrm{A} 1 / \partial \mathrm{t} 1+\partial \mathrm{A} 2 / \partial \mathrm{t} 2+\partial \mathrm{A} 3 / \partial \mathrm{t} 3]$

2.) $\partial \mathrm{R} / \partial \mathrm{t}=[\partial \mathrm{R} 1 / \partial \mathrm{t} 1+\partial \mathrm{R} 2 / \partial \mathrm{t} 2+\partial \mathrm{R} 3 / \partial \mathrm{t} 3]$.

Probability of spread:

$\mathbf{P}(\mathbf{A 1})=$ SpreadRateattime $(\mathrm{t}) / \mathrm{A} 1$ Population $=\mathrm{Z1} / \mathrm{A} 1(0)=500 /$ 1000 . $=\mathbf{0 . 5}$

$\mathbf{P}(\mathbf{A 2})=$ Spread $\quad$ Rate at time

(t) $/$ A2Population $=Z 2 / A 2(0)=300 / 1000=\mathbf{0 . 3}$

$\mathbf{P}(\mathbf{A 3})=$ Spread at time (t)/A3 Population $=\mathrm{Z} 3 / \mathrm{A} 3(0)=200 / 1000 \quad \boldsymbol{= 0 . 2}$

Comments on the PDE and Probability methods.

- The PDE 1 and 2 was employed to determine what group of people to give what palliative at what time .

- The Probability method tell us what degree of attention or quantity of palliatives to give the known group of people at this time.

\section{Constant of Integration}

The nature of constant of Integration depends on what more or less palliatives to give a particular group at a given time $(\mathrm{t})$.

This constant is denoted by $[\mathbf{k},-\mathbf{k}]$. whichever case we are dealing with at this time $(\mathrm{t})$. 
If $\mathbf{R}=$ (Palliatives),

k. =Constant of Integration (arbitrary),

e. $=$ exponential constant $=\mathbf{2 . 7 1 8}$

$\mathbf{R}(\mathbf{0})=$ Initial Resources(Palliatives),

t. =time,

Then, Resources(Palliatives) at any instant time $(\mathrm{t})$ is

\section{$R(t)=R(0) e^{\wedge} k t$. Or $R(t)=R(0) e^{\wedge}-k t$.}

https://youtu.be/K7L6Hsynexo

\section{CONCLUSION}

A simplified model to disease mathematical modeling was designed to address the negative impacts of COVID-19 on people such that their incomes were protected from total collapse, and disease diagnosis rates by testing, recovery rates among others are well improved.

There will be an unbiased treatment and decorum, Right people will be able to access right palliatives at the right time, Economy will be recalibrated, and more lives will be saved.

\section{ACKNOWLEDGEMENT}

I wish to thank Ureport Nigeria, Professor E.S. Adewole of University of Benin Nigeria, Engr.Olalekan Ajijola of Eljay consult constructing Limited,Nigeria and Mrs.Eunice Akeredolu (Mother) for their relentless encouragement.

\section{REFERENCES}

[1]. Stroud K.A etal (2011), Advanced Engineering mathematics,5th Edition.

[2]. Tom Leinster (2012), Reade survey: $\log |\mathbf{X}|+\mathbf{C}$, The ncategory Cafe.

[3]. https://youtu.be/K7L6Hsynexo 